\title{
HCMV infection triggers smooth muscle cell proliferation in a 3D human coronary in vitro model
}

Rainer Voisard ${ }^{*}$, Tanja Göttling², Regine Baur² and Vinzenz Hombach²

*Correspondence: rainer@voisard.de

1Department of Internal Medicine/Cardiology Krankenhaus Hammelburg, Ofenthaler Weg 20, D-97762 Hammelburg, Germany.

${ }^{2}$ Department of Internal Medicine II-Cardiology, University of Ulm, Albert-Einstein-Allee 23, D-89081 Ulm, Germany.

\begin{abstract}
Background: Although a role of the human cytomegalovirus (HCMV) in atherosclerosis and restenosis is probable, clinical studies are not conclusive. The present study investigates in a threedimensional (3D) human coronary transfilter co-culture model the effect of cell-free and cell-associated HCMV-infection.

Methods: Human coronary endothelial cells (HCAEC) and HCMSMC were seeded on both sides of a polycarbonate filter membrane. HCMV-infection was carried out by HCMV-infected MO. As controls MO-attack without HCMV-infection, cell free HCMV-infection, and the transfilter co-culture model without MO-attack and without HCMV-infection (Mock) were used.

Results: At day 1, day 4, day 7, and day 14 the effects of HCMV-infection on MO adhesion and chemotaxis and on reactive proliferation of HCMSMC was studied. Cell-associated HCMV infection of HCAEC and HCMSMC was less intense and postponed in comparison to cell-free HCMV infection. Endothelial adhesion of MO after cellbased HCMV infection was decreased in comparison to non-infected MO, no clear effect was found on chemotaxis. Both after cell-associated and cell-free HCMV infection proliferation of HCMSMC was significantly increased.

Conclusions: In the 3D human coronary transfilter co-culture model both cell-free and cell-associated HCMV-infection significantly increased proliferation of HCMSMC. If we assume that HCMV is involved in the pathogenesis of atherosclereosis and restenosis, the effect of antiviral treatments should be studied in experimental and clinical studies.
\end{abstract}

Keywords: HCMV, restenosis, atherosclerosis, transfilter co-culture model

\section{Introduction}

More than a decade ago Danesh et al., raised, in the light of increasing evidence that chronic infection is associated with atherosclerosis, the question: Is there a link between chronic infections and coronary artery disease? [1] Specific organisms, including herpesviruses, enhance atherosclerosis in the apolipoprotein $\mathrm{E}$ (ApaE)-deficient mouse [2,3]. Epidemiological studies have suggested an interaction between infection with the human cytomegalovirus (HCMV) and diabetes in promoting vascular disease [4]. HCMV has been associated with atherosclerosis, transplantation vasculopathy, vascular allograft rejection, and restenosis after angioplasty $[5,6]$.

Recently the group of Bentz et al., [7] demonstrated that HCMV infection triggers proliferation, migration, and morphogenesis in human endothelial cells. While it appears that HCMV contributes to the development of restenosis and atherosclerosis, there is no definitive proof that the virus causes as well an increased proliferation of smooth muscle cells. Rather, HCMV infection of human fibroblasts appears to trigger an opposite effect, namely, cell cycle arrest. In previous studies HCMV infection was shown to induce arrest of cell growth either in late G1 or in G2/M $[8,9]$. These findings conflict with reports that connected HCMV infection with the ability to promote an environment conducive to cell proliferation [10] and the induction of cellular proliferation [11]. In a recently described human ex vivo organ culture model of HCMV-infection [12] reactive cell proliferation after cellfree productive HCMV-infection was delayed but not increased [13].

The threedimensional (3D) human coronary transfilter coculture model mimics the inner layers of the vessel wall $[14,15]$. Endothelial cells and smooth muscle cells are cultured on both sides of a polycarbonate filter, through the filter pores the cells can communicate with eachother and move from one side to the other. Recently we have established this model $[16,17]$ with human coronary endothelial (HCAEC) and smooth muscle cells (HCMSMC). Adding of monocytes (MO) to the endothelial side of the model significantly stimulates cell proliferation of co-cultured HCMSMC [16]. In the current study we carry out both cell-free and cell-associated HCMV-infection of the 3D human coronary transfilter co-culture model and investigate the effect on $\mathrm{MO}$-adhesion/chemotaxis and the reactive proliferation of HCMSMC.

\section{Methods \\ Cell culture}

Human coronary media smooth muscle cells (HCMSMC, Cambrex Bio Science, Vervier, B) were cultured in Smooth Muscle Cell Growth Medium (Cambrex). For identification of HCMSMCs, monoclonal antibodies against smooth muscle a-actin were used (Sigma, Taufkirchen, D). Human coronary endothelial cells 
Voisard et al. Virology Discovery 2013,

(HCAEC, Cambrex) were grown in Endothelial Growth Medium (Cambrex). For identification of endothelial cells, antibodies against von Willebrand factor (Dakopatts, Hamburg, D) were used. MO were isolated from residual leukocytes of single donors using the MACS cell-isolation kit (Milteny Biotec, Bergisch-Gladbach, D).

\section{The 3D transfilter co-culture model}

The 3D human coronary transfilter co-culture model mimics the inner layers of human coronary arteries $[16,17]$. The internal elastic membrane is represented by a polycarbonate filter with a thickness of $10 \mu \mathrm{m}$ and a pore size of $5 \mu \mathrm{m}$ (Whatman, Göttingen, D). Filters were fixed in a specially designed frame and inserted in a siliconized culture dish. On both sides of the filters cell cultures were established, direct contact of the cultures was made possible through the pores of the filter.

HCMSMC were seeded on one side of the filter at a density of $2.5 \times 10^{4}$ cells $/ \mathrm{cm}^{2}$. After $24 \mathrm{~h}$ cells had attached to the surface and frame and filters were turned upside down. HCAEC were seeded on the opposite side of the filter at a density of $2.5 \times 10^{4}$ cells $/ \mathrm{cm}^{2}$. Both HCAEC- and HCMSMC-cultures were supplied with the appropriate culture medium and cultured for 14 days. At day 14 leukocyte attack was carried out by adding $3 \times 10^{5} \mathrm{MC}$ on the endothelial side of the units.

\section{HCMV-infection}

In the current study MO-attack in the 3D human coronary transfilter co-culture model was carried out by HCMV-infected MO. As controls MO-attack without HCMV-infection, cell free HCMV-infection, and the transfilter co-culture model without MO-attack and without HCMV-infection (Mock) were used.

For cellfree infection the endotheliotropic clinical HCMV isolate TB40E was used. $10 \mathrm{MOI}$ were added on the HCAEC side of the co-culture model. This isolate was kindly provided by Dr. Ch. Sinzger, University of Tübingen. Virus stocks were produced in human foreskin fibroblasts [12], infectivity was determined by plaque titration of stock virus [18]. Ten-fold dilutions of virus stocks were carried out in quadruplicate. After staining for viral late antigen (monoclonal antibody AAC10, DAKO, Glostrup, Denmark) viral infectivity was determined by plaque couting and was expressed as plaque forming $\mathrm{U} /$ $\mathrm{mL}$. Cell-associated HCMV infection was carried out with the same HCMV-strain as applied for cellfree HCMV-infection. For HCMV infection $3 \times 10^{5} \mathrm{MO}$ were incubated with $10 \mathrm{MOI}$ (multiplicity of infection) overnight.

\section{Adhesion and chemotaxis assays}

At day 1, day 4, day 7, and day 14 the effects of HCMV-infection on $M C$ adhesion and $M C$ chemotaxis were studied. Filters were fixed with $4 \%$ paraformaldehyde in phosphate-buffered saline ( $\mathrm{pH}$ 7.4) for $3 \mathrm{~h}$ at room temperatures; each filter was divided in 4 segments. One segment was used for the identification of MO. MO were identified with primary antibodies directed against CD68 (Dakopatts). TRITC-labeled antibodies (goat anti-mouse, Dianova) were used as secondary antibodies. The number of cells with positive staining against CD68 was detected horizontally after adhesion on the surface of HCAEC and after transmigration on the HCMSMC side of the 3DLAunits. For each investigation 10 microscopical fields of three different filters were analyzed (magnification, 40x).

\section{Identification of HCMV}

Identification of HCMV in the 3D transfilter co-cultures was carried out at day 1, day 4, day 7, and day 14 after infection with monoclonal antibodies against HMCV early antigen (Clon CCH2, Dakopatts). Alexa-Fluor 488-labeled antibodies (goat-anti-mouse, MoBiTel Göttingen) were used as secondary antibodies. The number of cells with positive staining against early antigen was detected horizontally on the surface of both the HCAEC- and the HCMSMC-side of the filter. For each investigation 10 microscopical fields of three different filters were analyzed.

\section{Cell proliferation assays}

At day 1, day 4, day 7, and day 14 the effects of HCMV-infection on reactive proliferation of HCAEC and HCMSMC was studied. $18 \mathrm{~h}$ before fixation, 5 bromo- 2 'deoxyuridine (BrdU, $20 \mu \mathrm{mol} / \mathrm{L}$, Serva) and 2'deoxy-cytidine ( $20 \mu \mathrm{mol} / \mathrm{L}$, Serva) were added to the culture medium of the transfilter co-culture units. One segment was embedded in Epon (Araldite, Serva) and was polymerized at $60^{\circ} \mathrm{C}$ for 3 days. For histological examination, semithin sections were mounted on poly-L-lysine-coated slips. One section was stained with toluidine blue (Merck). In another section, araldite was dissolved from the sections using potassium hydroxide dissolved in methanol and propylene oxide immediately before immunological staining. Proliferation was subsequently detected with monoclonal antibodies directed against BrdU (Dakopatts). For secondary antibodies, biotinylated goat anti-mouse antibodies were used. HCAEC were identified in a double staining with von Willebrand factor (Dakopatts) and a biotinylated goat antirabbit secondary antibody. In each group 10 sections of three filters were analyzed (magnification, 40x). The percentage of BrdU-positive HCMSMC and anti-von Willebrand factor positive HCAEC was calculated in relation to the total cell number.

\section{Statistical analysis}

The Mann-Whitney rank-sum test was used to investigate the significance of differences in HCMV identification and adhesion/chemotaxis assays of $\mathrm{MO}$ and in the proliferation assays of HCAEC and HCMSMC. Results are expressed as mean \pm SD. Differences were considered significant at $p<0.05$.

\section{Results \\ Description of HCMV-infection in the 3D transfilter co-culture model}

Time course and localization of HCMV early antigen was studied after cell-free and MO-associated HCMV-infection 
Voisard et al. Virology Discovery 2013,
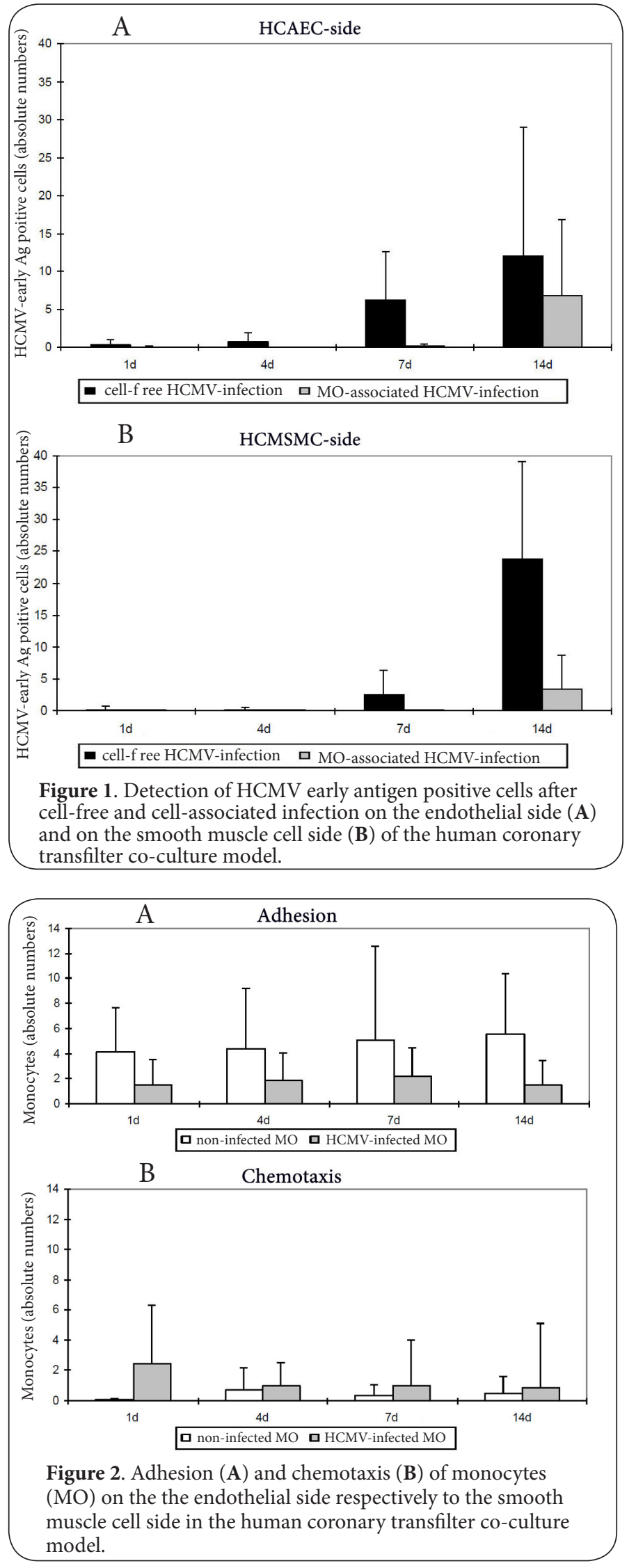

at day 1 , day 4 , day 7 , and day 14 . Both cell-free and cellassociated infection of the endothelial side and the smooth muscle cell side of the transfilter co-culture model with HCMV were successful. Cell-associated HCMSMC infection of both endothelial cells and smooth muscle cells was less intense and postponed in comparison to cell-free HCMV-infection (Figure 1A,1B, 4).

After cell-free infection little numbers of HCMV were detected on the endothelial side of the filters (Figure 1A). 7 days and 14 days after cell-free HCMV-infection the number of HCMV endothelial cells was increased 21-times $(p<0.001)$ and 40 -times $(p=0.001)$ in comparison to the number of HCMV detected at day 1 . After cell-associated infection very little numbers of virus were detected in endothelial cells at day 1, day 4, and day 7 after infection. At day 14 after infection the number of HCMV was strongly increased in comparison with the low numbers of virus detected until day $7(p<0.001)$.

On the smooth muscle side of the transfilter co-culture model (Figure 1B) very little numbers of infected cells were detected after cell-free HCMV infection at day 1 and day 4 . At day 7 a small but significant increase of HCMV positive HCMSMC was detected $(p<0.05)$ in comparison to the number of HCMV positive cells at day 1. At day 14 a strong increase of HCMV-positive cells was found ( $p<0.001$ in comparison to the number of HCMV positive cells at day 1). After cellassociated HCMV-infection no virus was detected at day 1 , day 4 , and day 7 after infection. At day 14 after cell-associated HCMV-infection a significant increase of HCMV-positive cells was detected $(p<0.001$ in comparison to the number of HCMV positive cells at day 1 ).

\section{Adhesion and chemotaxis of monocytes}

Adhesion of HCMV-infected MO on the endothelial side of the filters was decreased in comparison to non-infected $\mathrm{MO}$ (Figure 2A,4E), reaching statistical significance at day 1 and day 14. Chemotaxis of MO to the HCMSMC-side of the filters was very limited both in HCMV-infected and non-infected $\mathrm{MO}$ (Figure 2B).

MO-adhesion after cell-associated HCMV-infection was reduced in comparison to non-infected $\mathrm{MO}$ by $63 \%(\mathrm{p}<0.001)$ and $57 \%(\mathrm{p}=0.05)$ at day 1 and day 4 and by $58 \%$ (n.s.) and $72 \%(p<0.001)$ at day 7 and day 14 . Chemotaxis of MO was $0,0.7,0.35$ and 0.5 in the non-infected group and 2.47, 0.98, 1 , and 0.85 in the HCMV-infected group. At day one the differences between non-infected MO and HCMV-infected MO were significant $(p<0.001)$.

\section{Cell proliferation of HCAEC and HCMSMC}

Reactive cell proliferation of HCAEC and HCMSMC was studied after cell-free and MO-associated HCMV infection at day 1 , day 4 , day 7 , and day 14 . On the endothelial side of the filter very little proliferation was detected, no matter whether cell-free or cell-associated HCMV-infection was carried out (Figure 3,4C and 4F). On the smooth muscle side of the 
Voisard et al. Virology Discovery 2013,

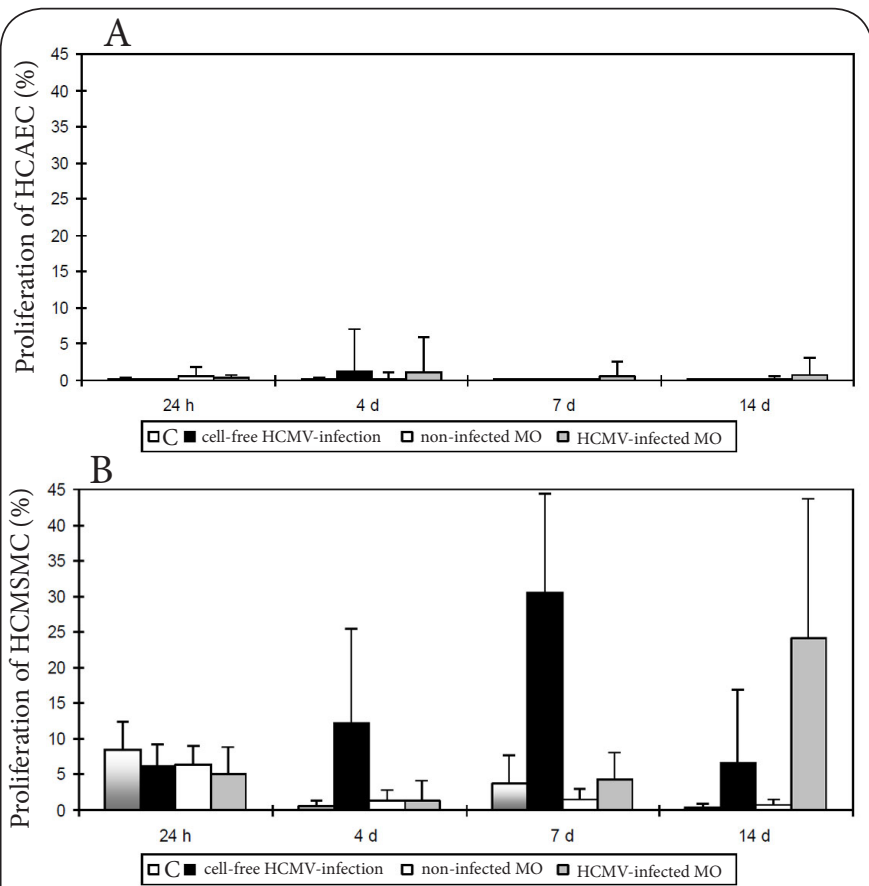

Figure 3. Reactive proliferation of human coronary endothelial cells (A) and co-cultured human coronary smooth muscle cells (B) after cell-free and cell-associated infection with HCMV.
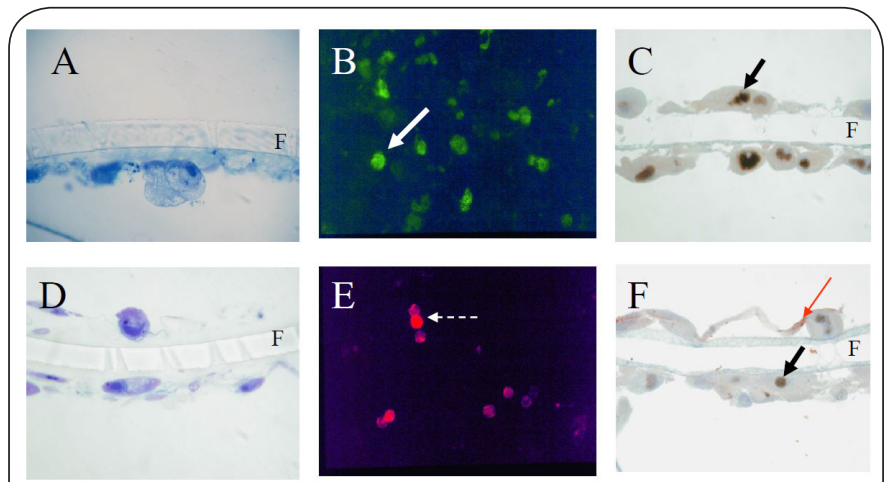

Figure 4. Cell-free (A,B,C) and cell-associated (D,E,F) HCMV infection of the human coronary transfilter co-culture model: (A) 14 days after cell-free HCMV infection, toluidin-blue staining, frontal cut through the filter membrane of the transfilter co-culture model, $\mathrm{F}=$ filter. (B) 14 days after cell-free HCMV infection, staining against HCMV early antigen, view from the top on the endothelial side of the filter membrane, $\mathrm{F}=$ filter. $(\mathrm{C}) 14$ days after cell-free HCMV infection, positive staining against BrdU for the analysis of reactive cell proliferation and against von Willebrand factor for the identification of endothelial cells, frontal cut through the filter membrane, black arrow $=$ BrdU-positive human coronary smooth muscle cells, F = filter. (D) 14 days after cell-associated HCMV infection, toluidin-blue staining, frontal cut through the filter membrane of the transfilter co-culture model, $\mathrm{F}=$ filter, bar $=40 \mu \mathrm{m}$. (E) 7 days after cell-associated HCMV infection, staining against CD68 for identification of monocytes, view from the top on the endothelial side of the filter membrane, white arrow. (F) 14 days after cell-associated HCMV infection, positive staining against BrdU (black arrow) for the analysis of reactive cell proliferation and against von Willebrand factor (red arrow) for the identification of endothelial cells. filters significantly increased levels of cell proliferation were detected, both after cell-free and cell-associated HCMV-infection. Cell-associated HCMV-infection caused a delay of reactive cell proliferation in comparison to cell-free HCMV-infection (Figure 3).

At day 1 the number of proliferating HCMSMC was very low in HCMV-infected cells and controls. Four and seven days after cell-free HCMV-infection proliferation of HCMSMC was increased by $97 \%$ (n.s.) and by $395 \%(p<0.001)$ in comparison to the number of proliferating cells at day 1 . At day 14 the number of proliferating cells returned to the baseline level found at day $1(p<0.01)$. After cell-associated HCMV-infection a delayed stimulation of cell proliferation was detected, cell proliferation was significantly decreased by $63 \%$ at day $4(p<0.001)$, reached baseline levels at day 7 and was significantly increased by $370 \%$ at day $14(p<0.001)$. In untreated controls and after adding of not-stimulated MO no increase of cell proliferation was detected (Figure 3 ).

\section{Discussion}

In the current study we investigated the effect of cell-free and $\mathrm{MO}$-associated HCMV-infection in a 3D human coronary transfilter co-culture model. Three major findings were determined: First, cell-associated HCMV infection of HCAEC and HCMSMC was less intense and postponed in comparison to cell-free HCMV infection. Second, endothelial adhesion of $\mathrm{MO}$ after cell-associated HCMV infection was decreased in comparison to non-infected $\mathrm{MO}$, no clear effect was found on chemotaxis. Third, both after cell-associated and cellfree HCMV infection proliferation of HCMSMC was highly increased.

Cytomegalovirus is a ubiquitous virus, as evidenced by the fact that the majority of adults throughout the world are seropositive for CMV (1). In immunocompromised subjects HCMV infection can cause serious diseases. With the exception of the mononucleosis-like syndrome it is generally believed that HCMV does not cause disease in healthy immunocompetent individuals. This may, however be incorrect. If HCMV plays a role in atherosclerosis and restenosis, it is critical to understand how HCMV is delivered to the vascular lesion and how the virus is activated from latency (5). In the current study we describe both cell-free and cell-associated HCMV-infection. Cell-free HCMV infection mimics the situation after HCMV infection of an individual. The endothelial layer of its vessel surface will get direct contact with the virus. Cell associated HCMV infection describes an alternative possibility suggested by recent studies focusing on the monocyte (5). Circulating monocytes have been shown to harbor CMV DNA (5). If the circulating HCMV-infected monocyte attacks the endothelial surface of the vessel wall we have a situation similar to the model of cell-associated HCMV infection.

In the current study cell-associated HCMV infection in HCAEC and HCMSMC was less intense and postponed 
in comparison to cell-free HCMV infection. This result was probably caused by the fact that the amount of virus load in cell-free HCMV infections was higly increased in comparison to the virus load in cell-associated HCMV infection. A comparable effect was already described following cell-free and cell-associated HCMV infection in the human arterial organ culture model (12).

Adhesion of HCMV-infected $\mathrm{MO}$ was reduced in comparison to non-infected MO. Altannavch et al., [21] studied the effect of HCMV on expression of ICAM-1, VCAM-1, and ELAM- 1 in HUVEC and described that HCMV increases expression of ICAM-1. These data are in contrast to data of the current study. For adhesion of $\mathrm{MO}$ expression of adhesion molecules is important not only at the surface of endothelial cells but although at the surface of MO. Gredmark et al., [22] recently demonstrated that HCMV infection of MO blocks the cytokineinduced cell differentiation, as a powerful tactic to avoid immune recognition at early phases of infection. Although there are no data in the literature on expression of adhesion molecules in $\mathrm{HCMV}$ infected $\mathrm{MO}$, it is possible that expression of adhesion molecules is decreased. Multifaceted interactions as increased expression of adhesion molecules in endothelial cells and decreased expression in MO can only be detected in complex in vitro models as the transfilter co-culture model.

Although a role of HCMV in atherosclerosis and restenosis is likely, the experimental proof is difficult. Earlier reports connected HCMV infection with the induction of cellular DNA synthesis and with the induction of an environment conducive to cell proliferation [10]. In a recent report the group of Dhaunsi reported that HCMV increases the serum induced proliferation of HCMSMC [11]. However there is no proof that the virus causes an increased proliferation of smooth muscle cells in a more complex environment as the transfilter co-culture model. The coronary transfilter coculture model allows a direct contact of HCAEC and HCSMC. Therefore interactions of these two cell types can be studied in an elegant manner, e.g. following cell-based or cell-associated HCMV infection, respectively.

Moreover, HCMV infection of human fibroblasts appears to trigger as well an opposite effect, namely, cell cycle arrest. In previous studies HCMV infection was shown to induce arrest of cell growth either in late $\mathrm{G} 1$ or in G2/M $[8,9]$.

In the 3D human coronary transfilter co-culture model reactive cell proliferation of co-cultured HCMSMC was increased significantly 3.9 times after cell-free HCMV infection and 3.7 times after cell-associated HCMV-infection in comparison to controls. The data proof that, in the complex experimental conditions of the human coronary transfilter co-culture model, cell proliferation is triggered after cellassociated and cell-free HCMV infection. Some evidence supports a link between the reactivation of latent HCMV following coronary angioplasty, p53 activation, and restenosis [23-25], as HCMV was preferentially detected in a subset of restenotic lesions that exhibited high levels of p53 protein
[25]. Dhaunsi et al., [11] suggested a role of NAPDH oxidase in cytomegalo-induced proliferation of HCMSMC.

In the present study maximal reactive cell proliferation occurred at day 7 after cell-free HCMV infection and at day 14 after cell-associated HCMV infection. This delay of reactive cell proliferation can be partially explained by the fact that $\mathrm{MO}$ based HCMC infection of both endothelial cells and smooth muscle cells was less intense and postponed in comparison to cell-free HCMV-infection. Moreover the data demonstrate that rather low numbers of $\mathrm{HCMV}$ are sufficient to trigger a strong proliferative response, reactive cell proliferation was almost identical after cell-free and cell-associated HCMV-infection.

Data of clinical studies comparing serum IgG and $\lg M$ antibodies to HCMV with the occurrence of restenosis following coronary intervention are contradicting. Both a clear correlation $[\mathbf{2 6 , 2 7 ]}$ between HCMV seropositivity and restenosis and no correlation at all $[\mathbf{2 8 , 2 9 ]}$ have been reported. Serum IgG and IgM antibodies to HCMV in individuals proof merely the presence of $\mathrm{HCMV}$ but do not indicate the ability or intention of the virus to stimulate $[10,11]$, postpone [13], or inhibit cell proliferation [8,9]. A different activity of HCMV in seropositive patients may be the explanation for the contradicting results in clinical trials, comparing seropositivity of individuals with the occurrence of restenosis or atherosclerosis. Recently Melnick et al., [30] suggested that upregulation of ERK phosphorylation is necessary for initial HCMV induced pathogenesis. The presented models are suitable for further studies on stimulatory and inhibitory effects of HCMV-infection in human coronary cells.

The 3D human coronary transfilter co-culture model is, despite its complexity, merely an in vitro model. Although HCAEC and HCMSMC are cultured as closed cell layers and are able to communicate with eachother, the model is a limited imitation of the human vessel wall. The effect of the adventia e.g. is completely missing. Human organ culture models are more complex, the reaction of the complete vessel wall consisting of endothelial layer, medial layer and adventitial layer can be studied. On the nother hand human organ culture models are limited by the fact that the nutrition vessels of the artery are cut during the preparation procedure. This may explain the fact that HCMV-infection (13) or perfusion with monocytes (31) did not trigger reactive cell proliferation, as recently described by our group.

$\mathrm{HCMV}$ is ubiquitous and persists after infection troughout the lifetime of the host. Although primary infection is usually asymptomatic, reactivation in immunocompromised individuals can cause severe disease. An immune system however is completely missing in the system. Taken together, data of the literature and the results of the present study demonstrate that infection with HCMV may influence the host cell cycle machinery in many different ways, depending on its actual interest. In the current study a link between HCMV infection and increased cell proliferation can be proofed, both after cell-free and cell-associated infection. 
Voisard et al. Virology Discovery 2013,

http://www.hoajonline.com/journals/pdf/2052-6202-1-2.pdf

doi: $10.7243 / 2052-6202-1-2$

If we assume that HCMV is involved in the pathogenesis of atherosclereosis, restenosis, and transplant vasculopathy the effect of antiviral treatment strategies should be elucidated in further studies.

\section{Competing interests}

The authors declare that they have no competing interests.

Acknowledgement and funding

The authors would like to thank Thomas Mertens,

Department of Virology, Institute of Microbiology and Immunology, University of Ulm, Germany, for technical support and helpful discussions of the data. This work was supported by the Deutsche Forschungsgemeinschaft

"Sonderforschungsbereich 451 ", project C1.

Publication history

Received: 11-Feb-2013 Revised: 09-Apr-2013

Accepted: 19-Apr-2013 Published: 23-Apr-2013

\section{References}

1. Danesh J, Collins R and Peto R: Chronic infections and coronary heart disease: is there a link? Lancet 1997, 350:430-6. | Article I PubMed

2. Alber DG, Powell KL, Vallance P, Goodwin DA and GrahameClarke C: Herpesvirus infection accelerates atherosclerosis in the apolipoprotein E-deficient mouse. Circulation 2000, 102:779-85. | Article | PubMed

3. Hsich E, Zhou YF, Paigen B, Johnson TM, Burnett MS and Epstein SE: Cytomegalovirus infection increases development of atherosclerosis in Apolipoprotein-E knockout mice. Atherosclerosis 2001, 156:23-8. | Article | PubMed

4. Sorlie PD, Nieto FJ, Adam E, Folsom AR, Shahar E and Massing $M$ : A prospective study of cytomegalovirus, herpes simplex virus 1 , and coronary heart disease: the atherosclerosis risk in communities (ARIC) study. Arch Intern Med 2000, 160:2027-32. | Article | PubMed

5. Popovic M, Smiljanic K, Dobutovic B, Syrovets T, Simmet $T$ and Isenovic ER: Human cytomegalovirus infection and atherothrombosis. J Thromb Thrombolysis 2012, 33:160-72. I Article | PubMed

6. Abele-OhI S, Leis M, Wollin M, Mahmoudian S, Hoffmann J, Muller R, Heim C, Spriewald BM, Weyand M, Stamminger T and Ensminger SM: Human cytomegalovirus infection leads to elevated levels of transplant arteriosclerosis in a humanized mouse aortic xenograft model. Am J Transplant 2012, 12:17209. | Article | PubMed

7. Bentz GL and Yurochko AD: Human CMV infection of endothelial cells induces an angiogenic response through viral binding to EGF receptor and beta1 and beta3 integrins. Proc Natl Acad Sci U S A 2008, 105:5531-6. | Article | PubMed Abstract | PubMed Full Text

8. Jault FM, Jault JM, Ruchti F, Fortunato EA, Clark C, Corbeil J, Richman DD and Spector DH: Cytomegalovirus infection induces high levels of cyclins, phosphorylated Rb, and p53, leading to cell cycle arrest. J Virol 1995, 69:6697-704. | Article | PubMed Abstract | PubMed Full Text

9. Lu M and Shenk T: Human cytomegalovirus infection inhibits cell cycle progression at multiple points, including the transition from G1 to S. J Virol 1996, 70:8850-7. | Article | PubMed Abstract | PubMed Full Text
10. Castillo JP, Yurochko AD and Kowalik TF: Role of human cytomegalovirus immediate-early proteins in cell growth control. J Virol 2000, 74:8028-37. | Article | PubMed Abstract | PubMed Full Text

11. Dhaunsi GS, Kaur J and Turner RB: Role of NADPH oxidase in cytomegalovirus-induced proliferation of human coronary artery smooth muscle cells. J Biomed Sci 2003, 10:505-9. | Article | PubMed

12. Reinhardt B, Vaida B, Voisard R, Keller L, Breul J, Metzger $H$, Herter T, Baur R, Luske A and Mertens T: Human cytomegalovirus infection in human renal arteries in vitro. $J$ Virol Methods 2003, 109:1-9. | Article | PubMed

13. Voisard R, Kruegers T, Reinhardt B, Vaida B, Baur R, Herter T, Luske A, Weckermann D, Weingartner K, Rossler W, Hombach $\mathrm{V}$ and Mertens T: HCMV-infection in a human arterial organ culture model: effects on cell proliferation and neointimal hyperplasia. BMC Microbiol 2007, 7:68. | Article | PubMed Abstract | PubMed Full Text

14. Betz E, Fallier-Becker P, Wolburg-Buchholz K and Fotev Z: Proliferation of smooth muscle cells in the inner and outer layers of the tunica media of arteries: an in vitro study. J Cell Physiol 1991, 147:385-95. | Article | PubMed

15. Roth DR, Axel DI and Betz EL: In vitro model of the inner parts of a vessel wall with cultured human vascular cells. Coron Artery Dis 1993, 4:283-91. | Article | PubMed

16. Voisard R, Voglic S, Baur R, Susa M, Koenig W and Hombach $\mathrm{V}$ : Leukocyte attack in a 3D human coronary in-vitro model. Coron Artery Dis 2001, 12:401-11. | Article I PubMed

17. Voisard R, Baur R, Voglic S, Hombach V: The human coronary transfilter co-culture unit: an in vitro model for cellular and molecular studies of human coronary restenosis. Perfusion 1998, 11:521-525.

18. Michel D, Pavic I, Zimmermann A, Haupt E, Wunderlich K, Heuschmid M and Mertens T: The UL97 gene product of human cytomegalovirus is an early-late protein with a nuclear localization but is not a nucleoside kinase. J Virol 1996, 70:6340-6. | Article | PubMed Abstract | PubMed Full Text

19. Fields N, Knipe DM, Howley PM, eds. Fields virology. LippincottRaven, Philadelphia; 1996:2447-2492.

20. Pignatelli S and Dal Monte P: Epidemiology of human cytomegalovirus strains through comparison of methodological approaches to explore gN variants. New Microbiol 2009, 32:1-10. I Pdf | PubMed

21. Altannavch TS, Roubalova K, Kucera $P$, Juzova $O$ and Andel M: Effect of human cytomegalovirus and glucose on adhesion molecules expression in cultured human endothelial cells. Acta Virol 2002, 46:183-6. | Article | PubMed

22. Gredmark $S$ and Soderberg-Naucler C: Human cytomegalovirus inhibits differentiation of monocytes into dendritic cells with the consequence of depressed immunological functions. $J$ Virol 2003, 77:10943-56. | Article | PubMed Abstract | PubMed Full Text

23. Epstein SE, Speir E, Zhou YF, Guetta E, Leon M and Finkel T: The role of infection in restenosis and atherosclerosis: focus on cytomegalovirus. Lancet 1996, 348 Suppl 1:s13-7. | Article | PubMed

24. Speir E, Huang ES, Modali R, Leon MB, Shawl F, Finkel T and Epstein SE: Interaction of human cytomegalovirus with $\mathrm{p} 53$ : possible role in coronary restenosis. Scand J Infect Dis Suppl 1995, 99:78-81. | PubMed

25. Speir E, Modali R, Huang ES, Leon MB, Shawl F, Finkel T and 
Epstein SE: Potential role of human cytomegalovirus and p53 interaction in coronary restenosis. Science 1994, 265:391-4. | Article I PubMed

26. Zhou YF, Leon MB, Waclawiw MA, Popma JJ, Yu ZX, Finkel T and Epstein SE: Association between prior cytomegalovirus infection and the risk of restenosis after coronary atherectomy. N Engl J Med 1996, 335:624-30. | Article | PubMed

27. Mueller C, Hodgson JM, Bestehorn HP, Brutsche M, Perruchoud $\mathrm{AP}$, Marsch S, Roskamm H and Buettner HJ: Previous cytomegalovirus infection and restenosis after aggressive angioplasty with provisional stenting. J Interv Cardiol 2003, 16:307-13. | Article I PubMed

28. Tiran A, Tio RA, Oostenveld E, Harmsen MC, Tiran B, den Heijer $\mathrm{P}$, Monnink SH, Wilders-Truschnig MM and The TH: Prior cytomegalovirus infection does not predict clinical outcome after percutaneous transluminal coronary angioplasty. Cardiology 1998, 90:263-8. | Article | PubMed

29. Neumann FJ, Kastrati A, Miethke T, Mehilli J, Pogatsa-Murray G, Koch W, Seyfarth $\mathrm{M}$ and Schomig A: Previous cytomegalovirus infection and restenosis after coronary stent placement. Circulation 2001, 104:1135-9. | Article | PubMed

30. Melnick M, Abichaker G, Htet K, Sedghizadeh P and Jaskoll T: Small molecule inhibitors of the host cell COX/AREG/EGFR/ERK pathway attenuate cytomegalovirus-induced pathogenesis. Exp Mol Pathol 2011, 91:400-10.. | Article | PubMed Abstract | PubMed Full Text

31. Voisard R, Baur R, Herter T, Krueger U, Breul J, Keller L and Hombach V: A perfused renal human organ culture model: impact of monocyte attack. Med Sci Monit 2007, 13:CR82-8. | Article I PubMed

\section{Citation:}

Voisard R, Göttling T, Baur R and Hombach V: HCMV infection triggers smooth muscle cell proliferation in a $3 \mathrm{D}$ human coronary in vitro model. Virology Discovery 2013, 1:2.

http://dx.doi.org/10.7243/2052-6202-1-2 